\title{
Do relacionamento entre Verdade e Retórica em Aristóteles
}

\author{
MARIA DE FÁTIMA SIMÕES FRANCISCO \\ Departamento de Filosofia e Ciências da Educação \\ Faculdade de Educação \\ Universidade de São Paulo
}

\begin{abstract}
RESUMO: Examinam-se no artigo duas passagens do início da Retórica de Aristóteles em que o autor, divergindo de Platão, enuncia a máxima utilidade dessa arte para a manifestação da verdade no tribunal e na assembléia. Alguns aspectos dessa verdade produzida retoricamente e do julgamento público, segundo a compreensão do filósofo, são apresentados.
\end{abstract}

PALAVRAS-CHAVE: retórica; verdade, julgamento público; investigação; persuasão pelos contrários; fundamentos da sociedade livre.

No primeiro capítulo da Retórica Aristóteles faz duas importantes colocações acerca do relacionamento entre retórica e verdade. Colocações essas que, malgrado seu peso para se compreender boa parte das motivações do filósofo em todo o tratado, não serão retomadas, nem aprofundadas depois. O propósito geral da passagem em que tais colocações ocorrem é o de proceder à defesa da retórica perante críticas como as de Platão, por meio da apresentaçâo de sua utilidade. A passagem tem assim um tom reconhecidamente antiplatônico. As duas colocações enfocam o valor positivo da retórica na manifestação da verdade e a perfeita compatibilidade entre o se propor essa manifestação e o fato de a retórica ser capaz de persuadir dos contrários'.

A primeira colocação pôde, graças à sugestão de tradução de W. Grimadi (Grimaldi, 1980, p. 25 ss.), assumir papel crucial na compreensão do projeto que Aristóteles reserva à retórica. Citemos a passagem que enuncia a primeira utilidade da retórica:

"A retórica é útil porque o verdadeiro e o justo são por natureza mais fortes que seus opostos; desse modo, se os julgamentos não são feitos da maneira conveniente, o verdadeiro e o justo são necessariamente vencidos por seus opostos. E isso é digno de censura" (1355a22-26)².

Temos, assim, que no julgamento público a tese que enuncia o verdadeiro e o justo é, por si mesma, naturalmente mais forte e tende a prevalecer sobre a que enuncia o falso e o injusto. Entretanto, para que essa superioridade se efetive, isto é, para que a tese verdadeira e justa resulte de fato vencedora, é necessário que o julgamento seja conduzido da maneira conveniente (kata to prosekon). Ora, é precisamente para uma tal condução que a arte retórica 
é útil. O julgamento transcorrerá da maneira conveniente se a tese verdadeira e justa for defendida por um orador que domine os recursos da arte retórica, domínio esse a ponto de permiti-lhe fazer ver ao público que se trata da tese verdadeira e justa. Não obstante a força natural superior da verdade e da justiça, elas apenas se darão a ver ao público se a sua força se aliar a força própria do discurso persuasivo. Na situação particular do julgamento público - que uma complexa configuração de elementos - a verdade e a justiça, malgrado sua superioridade, não podem, de forma alguma, para serem reconhecidas enquanto tais, prescindir dos préstimos da arte do orador.

Permitir, por outro lado, que a verdade e a justiça permaneçam ocultas e sejam vencidas pelo falso e a injustiça, tão somente por não se dominar os meios de fazê-las reconhecíveis, destaca Aristóteles, é censurável. Dispondo de uma vantagem, de saída, os que participam de julgamentos defendendo a tese justa e verdadeira teriam obrigação de fazê-la vencer. Para tanto bastaria que procurassem os meios de torná-la manifesta aos ouvintes, meios esses fornecidos justamente pela arte retórica. Para que a tese verdadeira e justa resulte vitoriosa, sugere a passagem em exame, será suficiente que o orador que a defende disponha de pelo menos tanta maestria em retórica quanto seu adversário, pois se beneficia da vantagem da tese mais forte. Para além do fato de ser condição sine qua non à realização dos debates que compõem os julgamentos na assembléia e no tribunal ${ }^{3}$, a retórica é útil, nos diz Aristóteles, por uma outra importante razão: é condição sine qua non para o ensejo, nesses julgamentos, da manifestação e vitória do verdadeiro e do justo. Aristóteles propõe assim claramente, e contra Platão, que, embora a retórica não seja a arte de produzir discursos científicos e verdades necessárias, nem mesmo sobre a justiça, constitui-se, entretanto, num aliado indispensável e insubstituível da verdade na situação particular do julgamento publico.

Ora, uma verdade não manifesta, não reconhecida, ainda que se trate de uma verdade, não tem qualquer utilidade, pois não produz qualquer efeito. Em se tratando de uma verdade de ordem prática e relativa ao interesse comum, tal como a que é discutida publicamente no tribunal e na assembléia, ainda mais relevante será a sua manifestação e reconhecimento. Nesse sentido, não basta à verdade com que se relaciona a retórica ser visível a um - o orador, por exemplo -, é necessário que o seja por todos ou pela maioria dos que participam no julgamento público. Na ordem das coisas práticas e discutidas publicamente, uma verdade que não é visível ao grande número deixa, por assim dizer, de ser uma verdade. Será tão somente uma simples opinião dentre outras. Para que o julgamento se processe da maneira conveniente não é, de modo algum, suficiente que o orador conheça a tese verdadeira e justa, isto é, que tenha bom discernimento, é preciso que saiba ainda como defendê-la e fazê-la visível aos demais, vale dizer, que seja um hábil orador.

O verdadeiro e o justo, não obstante sua superioridade natural em relação a seus opostos, não se manifestam necessariamente por si numa situação de julgamento, mas necessitam da arte retórica para isso. Emerge então a questão: que tipo particular de verdade é essa, própria do julgamento público? Para tentar responder a essa pergunta será útil nos determos em alguns elementos que Aristóteles faz intervir na noção, essencial para ele na Retórica, de julgamento

Notemos que o julgamento a que se refere Aristóteles na passagem em exame é bastante particular. É a atividade básica de duas instituições do regime democrático, o tribunal e a assembléia, instituições essas que reúnem a massa de cidadãos a fím de discutir pública e contraditoriamente os assuntos comuns e do interesse da cidade. A arte retórica 
proverá ao julgamento público a forma mais adequada de discurso. O discurso da ciência, por sua vez, tendo em vista a finalidade de comunicação com aquela massa, será inteiramente ineficaz. Alguém que conhecesse a verdade sobre um problema discutido na assembléia ou tribunal e dominasse acerca dele a mais alta ciência, ignorando, contudo, a arte própria do orador, não teria qualquer sucesso em comunicar tal verdade à massa, nem consequentemente em fazê-la reconhecível àquela. Nesse sentido, Aristóteles se poria de acordo com Górgias quanto a ter o conhecedor de retórica e leigo em determinada matéria mais sucesso em persuadir a massa acerca dessa matéria que o especialista nela e leigo em retórica ${ }^{4}$. De nada valeria, portanto, dispor da mais alta ciência e conhecer a verdade, se não se dominasse igualmente a arte de dirigir-se àquela massa e fazer tal verdade visível a ela.

Daí enunciar Aristóteles a segunda utilidade da retórica:

... além disso, ainda que tivéssemos a mais acurada ciência, não seria fácil utilizá-la para persuadir algumas pessoas. O discurso baseado na ciência é o ensino, mas ele é impossível com algumas pessoas; é necessário antes que as provas e argumentos sejam produzidos a partir das opiniões comuns, como dissemos nos Tópicos acerca da comunicação com multidões (1355a23-31).

A arte do orador pode prestar os maiores serviços justamente ali onde o mais fino conhecimento nenhuma serventia tem, vale dizer, quando se trata de se dirigir à multidão. Pois, destaca o filósofo como traço mais notável dessa multidão que enche as assembléias e os tribunais, a incultura, em suas várias manifestações ${ }^{5}$. Na comunicação com ela apenas as opiniões comuns (endoxa) - nem complexas, nem exatas, nem universais, nem abstratas podem ser eficazes. Ora, é precisamente do simples e impreciso, do conhecido e próximo à experiência do ouvinte que parte a retórica. Em consequiência, um aspecto a destacar dessa verdade acerca de que a retórica persuade é para quem ela está dirigida. Não se trata de forma alguma de um aluno ou discípulo, destinatário iniciado do discurso científico, mas da massa de cidadãos, em sua maioria inculta, que compõe o público das assembléias e tribunais. É de uma verdade feita à medida da compreensão desse público que se trata, qual seja, simples, particular, concreta e, num certo sentido, imprecisa. Podemos ver então que Aristóteles discordaria de Platão quanto à necessidade de o orador dominar, além da retórica, a episteme da justiça ${ }^{6}$.

O julgamento que tem lugar nessas reuniões de massa da democracia é apresentado por Aristóteles como uma investigação (skepsis) ${ }^{7}$ à qual se procede para saber o que ocorreu e o que ocorrerá, para se estabelecer uma verdade acerca dos fatos passados e futuros, obscuros e incertos que são. No tribunal, trata-se de investigar o que se passou, reconstituir o passado; na assembléia, o que se passará, antecipar o futuro ${ }^{8}$. O momento do próprio julgamento, da contagem de votos, é aquele em que, finda a investigação, define-se como os fatos se passaram ou passarão, define-se, enfim, a própria verdade. Ora, aquilo sobre o que se investiga e se decide, no passado e no futuro, são as próprias ações humanas ${ }^{9}$. Trata-se, portanto, de um lado, de uma verdade de ordem prática e, de outro, fruto da investigação coletiva pública.

A investigação no tribunal ocorre em razão de não ser evidente o que se passou, pois os fatos podem ter acontecido conforme reivindica cada uma das duas partes em conflito, queixoso e acusado. Por sua vez, é ainda menos evidente na assembléia que atitudes a 
cidade deverá tomar em dada circunstância, pois, sendo o futuro ignorado, as diferentes conjecturas aventadas acerca dele pelos discursantes são possíveis e plausíveis. Ora, aquilo que se investiga é obscuro justamente em virtude de pertencer à classe das coisas que sempre podem ser diferentes do que são, ou ainda, à do que não ocorre sempre da mesma forma e é necessário, mas sempre pode ser outro ${ }^{10}$. Trata-se, portanto, de uma verdade sobre o contingente.

Por fim, outro dado a destacar, o julgamento se dá em meio a uma disputa entre os discursantes, à controvérsia de seus pontos de vista acerca do mesmo caso ${ }^{11}$. É justamente em razão de tal disputa e discordância que o julgamento foi instaurado enquanto investigação. De maneira que, no tribunal, o acusado negará que houve falta, ou, se houve, que esta tenha sido prejudicial, ou, se foi, que o prejuízo tenha sido significativo, ou, se foi significativo, que tenha havido injustiça. Já seu oponente, o queixoso, afirmará ter ocorrido uma, algumas ou todas essas coisas ${ }^{12}$. Na assembléia, por sua vez, cada uma das propostas de ação apresentadas pelos oradores adversários, não obstante diferentes entre si, se pretendem, a mesmo título, a melhor e mais vantajosa para a cidade. Trata-se, portanto, de uma verdade estabelecida em meio à disputa e pela contraditoriedade dos pontos de vista. Em contraste com a dimensão de disputa em que transcorre o debate público, a verdade obtida ao final do julgamento aparece como fruto de um acordo, de um consenso, que se produz em torno de uma das proposições contraditórias que se apresentam. Trata-se, assim, de uma verdade publicamente acordada.

Retomemos então esse conjunto de aspectos que caracterizam a verdade própria da situação de julgamento. Vimos que tal verdade a) é composta de proposições simples, particulares, concretas e, até mesm.o, imprecisas; b) que concerne ao âmbito da ação humana e do contingente; c) que, dizendo respeito ao obscuro e incerto no passado e no futuro, é objeto de investigação; d) que é objeto de disputa, da contraditoriedade de discursos, e, finalmente, de consenso. Ora, é notável que essa verdade da situação de julgamento adotando a terminologia proposta por $\mathrm{F}$. Wolff ${ }^{13}$, a chamaremos dóxica, isto é, relativa ao domínio da doxa, da opinião - se opõe radicalmente à verdade epistêmica, que, tanto em Platão quanto em Aristóteles, tem por objeto o universal e o necessário, e não admite contradição. Vejamos agora porque a retórica é a arte do discurso mais apropriada para a manifestação de uma verdade com tais características.

Sendo essa verdade relativa ao particular, recorda-nos Aristóteles, não se poderá, para alcançá-la, buscar os préstimos de um conhecimento sistematizado ou de uma ciência determinada ${ }^{14}$. Porque cada caso em discussão na assembléia e no tribunal envolve uma configuração única de variáveis, é do particular que se trata. Mas sobre ele não pode haver conhecimento sistematizado $^{15}$. Por essa razão precisamente, o regime democrático fará dele assunto de investigação e deliberação coletivas, de discussão pública e controversa no tribunal e na assembléia. Daquilo sobre o que não pode haver ciência particular fará objeto de investigação comum - não menos rigorosa, em um certo sentido, que a científica - e de debate controverso.

Ora, a retórica demonstrará ser a arte do discurso a que é mais adequada às necessidades próprias da busca coletiva de uma tal verdade. Pois, de um lado, na medida em que permite a igual defesa de teses contraditórias, que admite a contraditoriedade, se ajusta perfeitamente às exigências do debate controverso. De outro lado, na medida em que tem por finalidade a persuasão, vale dizer, a incorporação pelos ouvintes de certa opinião como verdadeira, contribui igualmente para pôr fim à contraditoriedade e instaurar o acordo entre as partes em disputa ${ }^{16}$. 
A retórica, é preciso notar ainda, é uma arte em perfeita consonância com o princípio que governa as instituições democráticas nas quais se insere: possibilita o máximo de contraditoriedade, de diferença, de conflito enfim, no mínimo de violência. E isto em razão de o conflito se dar nessas instituições pelo discurso, pela palavra. Da mesma forma que possibilita, de outro lado, a administração das diferenças e dos conflitos por meio do alcance periódico do consenso. Para se alcançar a singularidade da ótica aristotélica sobre a retórica, é preciso ter presente essa solidariedade que estabelece entre a arte do orador e as instituiçõesbase do regime democrático nas quais é praticada. A retórica, bem como a verdade que ajuda a manifestar, são indissociáveis do regime democrático e não podem ser compreendidas senão à condição de se levar em consideração a relação básica que mantêm com ele.

A segunda colocação do primeiro capítulo da Retórica que tematiza o relacionamento entre retórica e verdade, retoma alguns pontos da primeira e acrescenta novos. Ela enuncia também a terceira utilidade da retórica:

Além disso, deveríamos ser capazes de persuadir sobre os dois lados de uma questão, tal como nos silogismos; não que possamos efetivamente persuadir de ambos (pois não deveríamos persuadir do que é vil), mas a fim de que não nos escape o real estado de coisas e de que possamos ser capazes de refutar aquele que vier por acaso usar o discurso injustamente. Nenhuma das outras artes produz silogismos acerca dos opostos; a dialética e a retórica são as únicas a fazê-lo, pois se relacionam igualmente com os opostos. O caso não é o mesmo, entretanto, com os fatos subjacentes; mas, o verdadeiro e o melhor são, de modo absoluto, por natureza sempre mais produtivos de bons silogismos e, numa palavra, mais persuasivos (1355a29-41).

Nessa passagem a intenção mais geral de Aristóteles parece ser, mais uma vez, a de afirmar o valor positivo da retórica para a manifestação da verdade. Trata-se agora em particular de mostrar que não há incompatibilidade entre o se propor tal manifestação e a persuasão dos contrários. Pois, na verdade, a possibilidade de persuadir dos contrários tem simultaneamente valor heurístico - em relação à verdadeira natureza do problema discutido -, e refutativo - em relação a uma eventual argumentação falaciosa do adversário. A retórica é útil, de um lado, porque a capacidade de persuasão dos contrários se converte em valioso meio de investigação e captação do real estado de coisas, dos fatos tal como se passaram ou passarão. De outro lado, porque essa mesma capacidade pode servir à refutação da tese falsa e à vitória da tese verdadeira.

Aristóteles observa ainda que a habilidade em persuadir dos contrários não deveria ser usada para maus fins, tal como seria a defesa do falso e do injusto. Evidentemente essa possibilidade não está descartada. O filósofo nota, contudo, num argumento a seguir, e mais uma vez contra Platão, que, se assim ocorrer, tal deporá não propriamente contra a arte retórica, mas antes contra a escolha que determinou esse uso ${ }^{17}$.

Na passagem citada, Aristóteles faz, por fim, uma ressalva plena de importância para nós: não obstante a retórica possa igual e indiferentemente persuadir da verdade dos contrários, esses próprios contrários não têm a mesma força persuasiva. Por ser, como a dialética, uma arte de prover argumentos, a retórica pode indiferentemente provê-los para mostrar verdadeira uma tese ou sua contraditória. Entretanto, aquilo de que os argumentos 
falam, os fatos subjacentes (ta hypokeimena pragmata), é de uma só natureza e, em consequiência, capaz de tornar uma tese verdadeira e sua contraditória falsa. $\mathrm{O}$ acordo ou desacordo com os fatos subjacentes influi diretamente sobre a persuasividade das teses, de modo tal que aquela que estiver em conformidade com eles será superior em força persuasiva relativamente a sua contraditória. Aristóteles está aqui retomando, e desta feita justificando, a idéia, já exposta na primeira colocação acerca do relacionamento entre verdade e retórica, de que o verdadeiro e o justo são por natureza mais fortes que seus opostos.

Um orador pode, se quiser, defender a tese falsa. Contudo, seu adversário, o defensor da tese verdadeira, se for ao menos tão hábil em retórica quanto ele, será melhor sucedido em persuadir. Eis, portanto, por que nosso filósofo não acredita no poder ilimitado e irresistível do orador inescrupuloso, tão temido por Platão. Pois pensa que, além de depender da habilidade do orador, a força de uma tese depende também e fundamentalmente da relação que estabelece com a realidade das coisas. Temos assim que tanto a habilidade técnica do orador quanto o acordo de uma proposição com os fatos subjacentes podem contribuir para a vitória da tese verdadeira. A melhor garantia para tanto advirá, entretanto, da associação entre esses dois fatores.

O que Aristóteles parece querer indicar é que a força da própria realidade das coisas pode, se estiver presente determinada condição, neutralizar os eventuais efeitos nocivos da indiferença da retórica em relação aos contrários, isto é, da capacidade de persuadir tanto do verdadeiro quanto do falso. A condição a satisfazer será, como vimos, a de que o orador que defende a tese verdadeira tenha pelo menos tanta maestria em retórica quanto seu oponente. O tribunal e a assembléia não são então, como imaginava Platão, cenários em que líderes políticos mal-intencionados se valem de sua habilidade em persuadir para dirigir a seu bel prazer a massa de cidadãos, sem encontrar qualquer força capaz de resistir-lhes. O filósofo pensa, ao contrário, que pode haver sim resistência a esses oradores. Tal ocorrerá desde que seus oponentes dominem também e na medida necessária a arte de se comunicar com a massa de cidadãos. Ao invés de ser vista como a arma poderosa de políticos inescrupulosos e demagógicos que se põem em chefes do povo e tiranizam-no, como pensava Platão, a retórica será vista como a arte que pode estar a serviço da preservação dos fundamentos da sociedade livre ${ }^{18}$. Para tanto será necessário que os políticos bem intencionados aprendamna e que a filosofia dela se ocupe, sistematizando-a de forma a torná-la acessível àqueles.

Tal é, parece-nos, o sentido mais profundo do projeto de Aristóteles no tratado da Retórica. $\mathrm{O}$ vasto material de argumentação que reúne, enquanto manual de retórica que também é, pode, sem dúvida, ser usado pelo orador mal intencionado e desonesto, mas é, sobretudo, ao adversário deste que se dirige. Que o defensor da tese verdadeira e justa seja ao menos tão hábil orador quanto seu oponente quer dizer inclusive, note-se, que seja capaz de imitá-lo quando aquele usar artifícios excusos e argumentos falaciosos, caso em que a balança pode pender para o lado da vitória do falso e da injustiça. É assim, parece-nos, que se pode entender as passagens da Retórica em que o filósofo apresenta tais artifícios e argumentos. A intenção de pô-los ao alcance do orador honesto, para a eventualidade de seu adversário vir a lançar mão deles, pode explicar o aparente desprendimento ético que se vê em determinadas passagens do tratado. Se for necessário ao orador honesto usar de demagogia e de um discurso falacioso será porque seu adversário, para defender o falso e a injustiça, já utilizou tais meios ou pode vir a fazê-lo. Em tais circunstâncias, o uso desses recursos pelo orador honesto será plenamente justificado, pois se pretende que desses recursos possa resultar a vitória da verdade, da justiça e do melhor. É necessário, portanto, quando nos surpreendemos 
diante da aparente amoralidade das sugestões da Retórica, notar que talvez Aristóteles esteja nos dizendo que a arte retórica obedece, por assim dizer, a uma ética mais complexa do que se pode esperar à primeira vista. Ética essa que, entretanto, em lugar de conflitar com a perspectiva ética que atravessa a obra aristotélica, na verdade se harmoniza integralmente com ela.

\section{Notas}

1 - Tal é o ponto nodal da crítica platônica à retórica no Górgias. Sendo o orador capaz de persuadir tanto do justo, do nobre e do bem quanto do injusto, do vergonhoso e do mal, vige nessa arte uma indeterminação em relação a seus fins. Indeterminação essa que é, por sua vez, inadmissível numa verdadeira arte. Veja-se 459c e ss. para a demonstração de que a retórica só poderia ser uma verdadeira arte se persuadisse apenas do justo, do nobre e do bem A essência da crítica platônica diz respeito ao estatuto ético dessa arte.

2 - A tradução das passagens de Aristóteles é nossa.

3 - Veremos a seguir que essa é a segunda utilidade da arte retórica

4 - V. Platão, Górgias, 459b10-14.

5 - São várias as passagens da Retórica em que Aristóteles faz referência à incultura do público: 1357a2-3; 1357a11-12; 1395b1-2; 1395b24-31; 1415b5-6; 1419a18-19; 1419b30. Também Platão reconhece no Górgias a dificuldade em instruir a multidão, v. 455a4-8. As implicações da incultura na retórica são discutidas por nós no terceiro capítulo de nosso trabalho de doutorado, devendo ser publicado em artigo

6 - V. por exemplo Górgias, 460a6. Poderíamos, ainda, se quiséssemos encontrar aí uma razão para a diferença de tratamento das noções éticas entre os textos éticos de Aristóteles e a Retórica. A precisão, profundidade, exaustividade e invariabilidade dos conceitos são requisitos do discurso científico, mas impróprias e mesmo inconvenientes no discurso retórico.

7 - V. por exemplo "a maior parte das coisas acerca das quais são os julgamentos e as investigações (skepseis) podem ser outra do que são; pois deliberamos e investigamos (skopousi) acerca das ações humanas;" 1357a25-29. A idéia de investigação é sugerida também em 1359b1-3.

8 - V. 1358b4-6 e 1358b14-23.

9 - V. $1357 \mathrm{a} 25-31$.

10 - V. 1357a25-31 e 1357a7-11. Sobre a obscuridade dos fatos passados: 1368a32.

11 - O julgamento no tribunal e na assembléia assume o sentido de disputa entre as partes que discursam. Aristóteles emprega repetidamente o termo disputa (amphisbetesis) para qualificar o que ocorre no tribunal. A variante disputante é usada, por exemplo, para designar as partes num tribunal

12 - Tais são os quatro pontos em disputa no tribunal. V. 1417b10-13.

13 - Essa terminologia está presente num texto inédito sobre as chamadas "técnicas discursivas de verdade”, exposto em seminário na École Normale Supérieure.

14 - Sobre não haver conhecimento sistematizado acerca da matéria com que lida a retórica: "a função da retórica está relacionada com o tipo de coisas acerca das quais deliberamos e para as quais não dispomos de artes", 1357a2. 
15 - Sobre não haver ciência do particular: "nenhuma arte investiga o particular - por exemplo a arte da medicina não investiga o que é saudável para Sócrates ou Cálias, mas para pessoas de um certo tipo (tal é o pertinente a uma arte, os particulares, por sua vez, são sem fim e não passíveis de conhecimento)", 1356b30-35.

16 - Poder-se-ia mencionar ainda que, sistematizando uma série de recursos discursivos sobre como dizer algo a uma massa numerosa e inculta - o que Aristóteles chamará de estilo (lexis) - a retórica torna possível, mais uma vez, a busca coletiva dessa verdade. A teoria aristotélica do estilo retórico é discutida no terceiro capítulo de nossa tese de doutorado, já aludido

17 - V. 1355b15-19.

18 - Richard Bodeüs chama atenção para o fato de que a retórica é útil e necessária, segundo Aristóteles, à perpetuação da sociedade política livre que a democracia representa. Assume assim suma importância não apenas por motivos éticos - para fazer vencer a tese justa e verdadeira, e de modo geral os propósitos do orador honesto -, mas também por motivos políticos - para impedir que sejam minados os fundamentos da sociedade política livre. V. "Des raisons d'être d'une argumentation rhétorique selon Aristote", in Cahiers du Département de Philosophie de l'Université de Montréal, nº 8804, 1988, p. 8.

\section{Referências bibliográficas}

ARISTOTLE, Art of Rhetoric, trad. J. H. Freese, coleção Loeb Classical Library, Cambridge, Massachusetts: Harvard University Press/ London: William Heinemann Ltd, 1975, 1. ed. 1926.

BODEÜS, Richard. "Des raisons d'être d'une argumentation rhétorique selon Aristote”. In: Cahiers du Département de Philosophie de l'Université de Montréal, nº 8804, 1988. p. $46-54$.

GRIMALDI, William M. A. Aristotle, Rhetoric I, A Commentary. New York: Fordham University Press, 1980.

PLATON, Gorgias. Paris: Les Belles Lettres, 1935

FRANCISCO, Maria de Fátima Simões. On the relationship between truth and rethoric on Aristotle. Classica, São Paulo, 11/12, 289-296, 1998/1999.

ABSTRACT: We examine in this article two passages in the beginning of Aristotle's Rhetoric. In: them the philosopher disagrees of Plato and states the utility of rhetorical art to the manifestation of the truth in the tribunal and assembly. Some aspects of this rhetorically produced truth and of the public jugdement are then presented.

KEY-WORDS: rhetoric; truth; public judgement; investigation; persusion through contraries; free society foundations. 